\title{
Influence of the kinetic demixing of cations on ceramic ageing and alloy corrosion (*)
}

\author{
C. Petot $\left({ }^{1}\right)$, G. Petot-Ervas $\left({ }^{1}\right)$, D. Monceau $\left({ }^{1}\right)$ and H. Klimczyk $\left({ }^{2}\right)$ \\ ( ${ }^{1}$ CNRS, LPCM-UPR 211, Université Paris XIII, 93430 Villetaneuse, France \\ $\left({ }^{2}\right)$ Inst. of Metallurgy, Academy of Mining and Metallurgy, Krakow, Poland
}

\begin{abstract}
This paper concerns the kinetic demixing of cations in semiconducting oxides. From the general equations of matter transport, time-dependent cation redistributions are given for $(\mathrm{Co}, \mathrm{Mg}) \mathrm{O}$ and $(\mathrm{Fe}, \mathrm{Cr}) \mathrm{O}$ solid solutions for which thermodynamical and kinetic data are available. The cation kinetic demixing effects on the reaction rates are described. The conclusions are used to analyse the behavior of $(\mathrm{Fe}, \mathrm{Cr}) \mathrm{O}$ solid solutions under a chemical potential gradient and the effect of $\mathrm{Cr}$ on the internal oxidation of $\mathrm{Ni}-\mathrm{Cr}$ alloys.
\end{abstract}

\section{Introduction.}

Wagner [1] was the first to relate the distribution of cations in oxide solid solutions to their mobility and to describe the growth of oxidation scales on binary alloys. A computer solution of the Wagner equations has been made by Narita $e t$ al. [2]. These authors have estimated the reaction kinetics and calculated the cation concentration profiles in the oxidation scales formed on Co-Fe and Co-Ni alloys. Nevertheless, the fitting of the experimental data to the parabolic kinetics predicted by the model of Wagner is possible only for some particular cases. This is due to the complexity of the overall corrosion process.

In the present work we have considered only the transport processes within the range of stability of the oxide, in order to avoid the kinetic factors due to the substrate in alloy corrosion. The general equations of the matter transport will be given. Kinetic demixing calculations have been done for transition metal oxides. The conclusions will be used to analyse experimental results.

\section{Statement of the problem.}

For a quantitative description of the transport processes, the dominant defects have to be specified. As an example, we have reported in figure 1 the various defect concentrations as a function of the oxygen partial pressure $\left(a_{\mathrm{O}}=P_{\mathrm{O}_{2}}{ }^{(1 / 2)}\right)$, for CoO pure and doped with chromium. These results show that isolated doubly-ionized cationic vacancies (simple defect model) are possible only at very low $P_{\mathrm{O}_{2}}\left(<10^{-5} \mathrm{~atm}\right)$. In this analysis the interactions among defects have been assumed to lead to the $4: 1$ clusters [3-4] formed by the tetrahedral aggregate of four vacancies with a cobalt $\left(\mathrm{C}^{\alpha^{\prime}}\right)$ or a chromium $\left(\mathrm{T}^{\alpha^{\prime}}\right)$ in interstitial position.

$(*)$ Invited paper. 
One may point out that the interactions among defects may also be analysed on the basis of the Debye-Hückel model considering only cationic vacancies doubly ionized in interaction with the surrounding environment [4]. The exact description of the defects is still an open problem. Nevertheless, from a thermodynamical point of view the two approaches are equivalent [4]. Consequently, to have a description of the transport processes under thermodynamical potential gradients [5-7], we have considered a semi-conducting oxide solid solution $(\mathrm{AO}, \mathrm{BO} \gamma)$ in which diffusion is mainly controlled by cationic vacancies with an average charge $\alpha$. These vacancies $\left(\mathrm{V}^{\alpha^{\prime}}\right)$ can be isolated defects or vacancies in interaction with
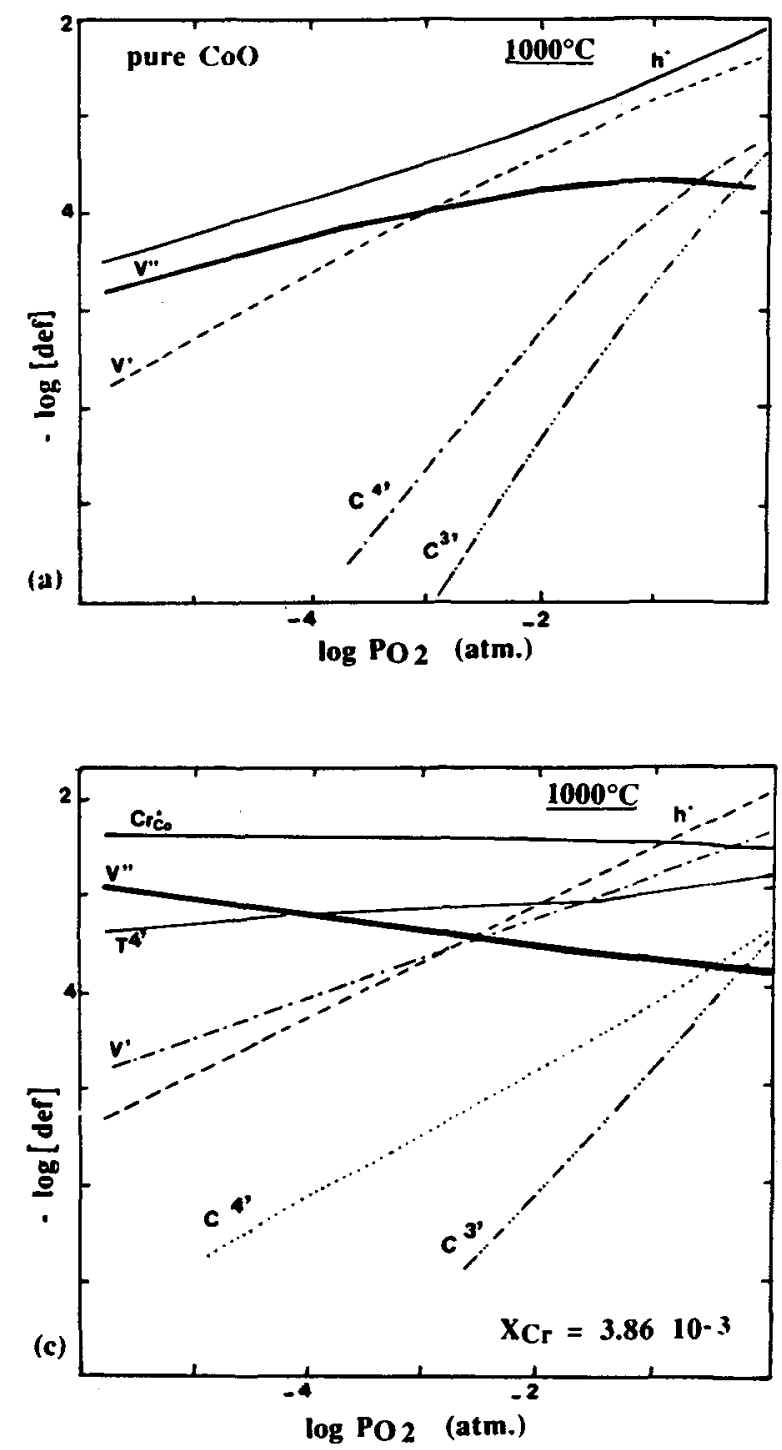

Fig. 1. - Calculated concentrations of the various defects in $\mathrm{CoO}$ pure and doped with $\mathrm{Cr}\left(x_{\mathrm{Gr}}=\right.$ $3.86 \times 10^{-3}$ ) as a function of $P_{\mathrm{O}_{2}}$, at $1000^{\circ} \mathrm{C}$ [3]. 
the surrounding environment (atoms or defects). Taking into account the equation of formation of the defects $\left(1 / 2 \mathrm{O}_{2} \leftrightarrows \mathrm{V}^{\alpha^{\prime}}+\alpha \mathrm{h}^{\circ}+\mathrm{O}_{\circ}\right)$, it is possible to express their concentrations as a function of the thermodynamical equilibrium parameters, $T$ and $P_{\mathrm{O}_{2}}$ :

$$
K=\left[\mathrm{V}^{\alpha^{\prime}}\right]\left[\mathrm{h}^{\circ}\right]^{\alpha} / P_{\mathrm{O}_{2}}{ }^{1 / 2}
$$

After an abrupt change of the thermodynamical equilibrium conditions, a defect relaxation occurs in the material. This leads to an irreversible flow of vacancies through the end surfaces, accompanied by a flow of cations in the sample and by the creation or annihilation of lattice sites on the end surfaces. A shift of the crystal occurs then with respect to the laboratory reference frame and the drift velocity of the end surfaces is directly related to the flux of vacancies $[1,5-9]\left(\right.$ when $\left.\left[\mathrm{V}^{\alpha^{\prime}}\right]<<1\right)$ :

$$
v=-J_{\mathrm{V}} / c_{\mathrm{M}}
$$

Simultaneously, a flux of vacancies $\left(J_{\mathrm{V}}\right)$ coupled to an opposite flux of cations $\left(J_{\mathrm{i}}\right)$ occurs in the bulk of the material:

$$
J_{\mathrm{V}}+\Sigma J_{\mathrm{i}}=0
$$

In previous papers [5-7] we have shown that the driving force of diffusion $(F)$ can be related to the vacancy concentration gradient $\left(\delta \ln \left[\mathrm{V}^{\alpha^{\prime}}\right] / \delta x\right)$ i.e. either to the gradient of oxygen activity or to the gradient of temperature [7]:

$$
\begin{aligned}
& F=R T(1+\alpha)\left(\delta \ln \left[\mathrm{V}^{\alpha^{\prime}}\right] / \delta x\right)_{T}=R T \delta \ln a_{\mathrm{o}} / \delta x \\
& F=R T(1+\alpha)\left(\delta \ln \left[\mathrm{V}^{\alpha^{\prime}}\right] / \delta x\right)_{P_{\mathrm{O}_{2}}}=\Delta H_{\mathrm{f}}(\delta \ln T / \delta x)
\end{aligned}
$$

Assuming that the fluxes are independent, we have obtained:

$$
J_{\mathrm{i}}=D_{\mathrm{i}}\left(-\delta c_{\mathrm{i}} / \delta x+c_{\mathrm{i}} \gamma(1+\alpha) \delta \ln \left[\mathrm{V}^{\alpha^{\prime}}\right] / \delta x\right)
$$

where $c_{\mathrm{i}}$ is the concentration of cations $\mathrm{A}^{2+}$ or $\mathrm{B}^{\gamma / 2+}$ and $\delta c_{\mathrm{i}} / \delta x$ is the cation concentration gradient which develops in the material if the exchange frequencies between the vacancies and the neighbouring cations $\mathrm{A}^{2+}$ or $\mathrm{B}^{\gamma / 2+}$ are different [1, 5-9].

\section{Kinetic demixing calculations.}

3.1 CONSTANT THERMODYNAMICAL POTENTIAL GRADIENT. - One can recall that the time needed by a vacancy to percolate through the entire length of the crystal $\left(t_{\mathrm{v}}\right)$ is short compared to that needed by a cation. As an example, for a $(\mathrm{Co}, \mathrm{Mg}) \mathrm{O}$ sample of $1 \mathrm{~mm}$ length, $t_{\mathrm{v}}$ has been found lower than half an hour at $1439^{\circ} \mathrm{C}$, while the time needed to reach the steady state condition for the cations (Fig. 2) is higher than $300 \mathrm{~h}$. Calculations have then been done assuming that the vacancy concentration has reached the steady state. This corresponds to the condition $F=c t$. 
As an example, we have reported in figure 2 calculated cation distribution profiles in an initially homogeneous $(\mathrm{Co}, \mathrm{Mg}$ ) O sample (where $m=0.49$ is the molar concentration of $\mathrm{MgO}$ ) exposed under a constant oxygen potential gradient. These results show that it takes more than $300 \mathrm{~h}$ to reach the steady state. A good agreement has been observed with the experimental data of Schmalzried et al. [5-8] obtained after an annealing time of $136 \mathrm{~h}$. We have done the same calculations under a constant temperature gradient. The agreement with the experimental results is good excepted near the side exposed to the higher temperature. This is probably due to a $\mathrm{CoO}$ evaporation [9].

3.2 THERMODYNAMICAL POTENTIAL GRADIENT FUNCTION OF TIME. - In oxidation layers, or in the first stage of the oxidation (or reduction) process of an oxide within its range of stability, the vacancy concentration is locally a function of time. Calculations have then been done taking into account that the driving force of diffusion is not constant $[7,9](F=f(x, t))$. As an example, we have reported in figure 3 the results we have obtained with a wustite sample of $3 \mathrm{~mm}$ length doped with chromium [10]. The sample previously in thermodynamical equilibrium under an oxygen partial pressure of $6.04 \times 10^{-13} \mathrm{~atm}$. has been reduced under an oxygen partial pressure equal to $8.5 \times 10^{-14} \mathrm{~atm}$.

\section{Cation demixing effect on the reaction kinetics.}

From the previous equations it is possible to estimate the shift velocity of the reaction front in the material. Neglecting the small changes of volume due to the solute and vacancy concentration variations, we have obtained [5-7]:

$$
v=-\left(\gamma D_{\mathrm{B}}-D_{\mathrm{A}}\right)\left(m \delta \ln a_{\mathrm{O}} / \delta x-\delta m / \delta x\right)+D_{\mathrm{B}}(1-\gamma) \delta m / \delta x-D_{\mathrm{A}} \delta \ln a_{\mathrm{O}} / \delta x
$$

It follows from this equation that the reaction rate $(v)$ depends on the kinetic demixing of the solute cations $B^{\gamma / 2+}(\mathrm{d} m / \mathrm{d} x)$. As an example, for an oxide in which $\gamma D_{\mathrm{B}}<D_{\mathrm{A}}$ (with $\gamma<1$ ), an enrichment of the cations $B^{\gamma / 2+}$ must be observed near the side exposed to the lower $P_{\mathrm{O}_{2}}$, if the correlation effects can be neglected. Taking into account that the last term in equation (7) represents the shift velocity of the reaction front in the pure oxide, this equation shows that the cation redistributions must lead to a decrease of the oxidation or reduction kinetics of the oxide.

\section{Experimental results.}

5.1 Kinetic DEMIXING OF FeO DOPED WiTH Cr. - Figure 4 shows the chromium segregation profile near the metal/oxide interface and the morphology of the partially reduced doped wustite sample $\left(1000 \mathrm{ppm}\right.$ in weigth) after $2 \mathrm{~h}$ of reduction at $1113^{\circ} \mathrm{C}$. The partial reduction experiments have been performed on single crystals previously annealed in a $50 \% \mathrm{CO} / 50 \%$ $\mathrm{CO}_{2}$ mixture [3]. We have observed that once formed the thickness of the iron scale seems not to increase with time. The scale seems to form an impervious shell around the oxide whose reduction occurs then within its range of stability. In agreement with our formal treatment and with the cation diffusion coefficient values in $\mathrm{FeO}$ [3] $\left(D_{\mathrm{Cr}}<D_{\mathrm{Fe}}\right)$, an increase of the chromium concentration is observed near the metal/oxide interface. According to equation (7), a decrease of the reactions kinetics must then be observed when wustite is doped with Cr. This conclusion is confirmed by the experimental results of Levin et al. [11]. 


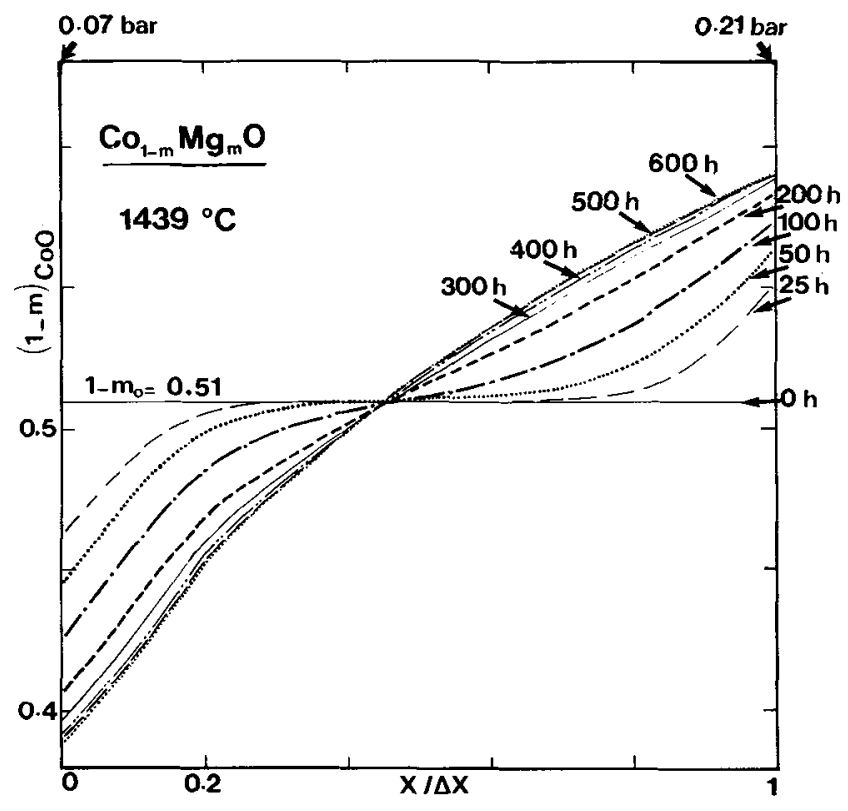

Fig. 2. - Time evolution of the kinetics demixing in a ( $\mathrm{Co}, \mathrm{Mg}) \mathrm{O}$ sample annealed in an oxygen potential gradient included between 0.07 and 0.21 bar.

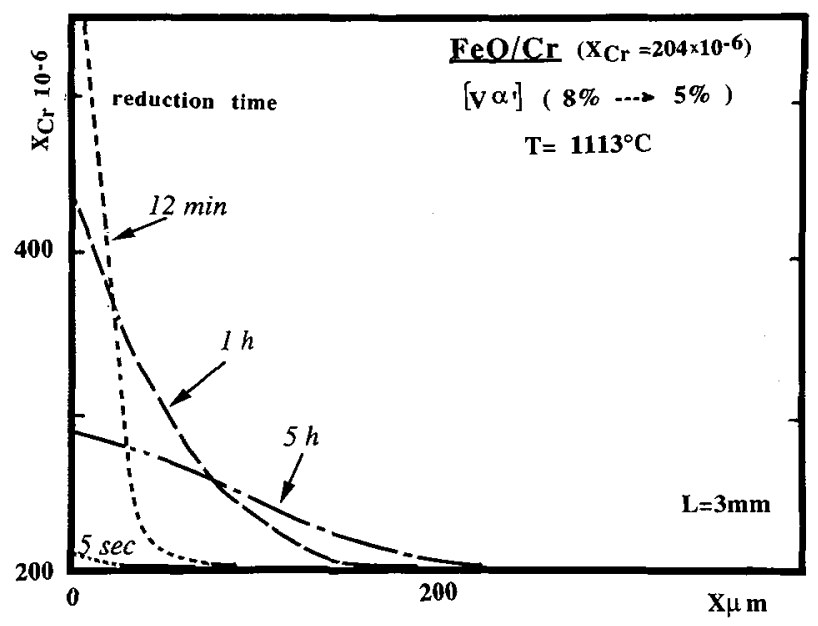

Fig. 3. - Calculated chromium kinetic demixing profiles during the re-equilibration process of a $\mathrm{Cr}$ doped wustite sample. 


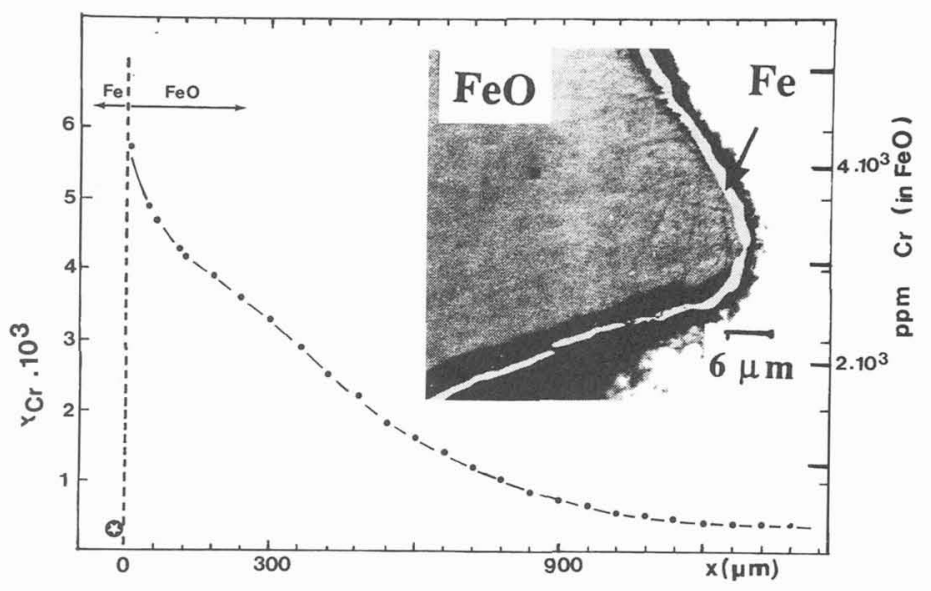

Fig. 4. - Chromium segregation profile near the metal/oxide interface and morphology of the iron layer.

5.2 INFLUENCE OF THE KINETIC DEMIXING OF Cr IN THE SCALE ON THE DEPTH OF PENETRATION OF THE INTERNAL OXIDATION FRONT IN Ni/Cr ALLOYS. - In this analysis any assumption has been made on the thickening of the oxide scale (parabolic or linear) contrary to the previous works (reported in [12]). We have consider only the influence of the kinetic demixing of the solute cations in the scale on the rate of advancement of the oxidation front in the scale and therefore in the alloy $[3,4,10]$.

An extensive study of the oxidation of $\mathrm{Ni} / \mathrm{Cr}$ alloys ( 1 to $5 \mathrm{wt} \% \mathrm{Cr}$ ) has been performed by Stott et al. [13]. During the oxidation process a NiO layer develops at the surface of the alloy while small precipitates of chromium oxide form in the subjacent alloy. These authors have observed that the depth of penetration of the internal oxidation front decreases when the $\mathrm{Cr}$ concentration increases in the alloy. This observation is consistent both with the experimental results of Nowotny et al. [14], who have observed a decrease of the redox kinetics in presence of $\mathrm{Cr}$ in the stability range of $\mathrm{NiO}$, and with our formal treatment [6], who suggests a decrease of the shift velocity of the oxidation front (Eq. (7)) when the $\mathrm{Cr}$ concentration increases due to the relative diffusion coefficient values of $\mathrm{Ni}$ and $\mathrm{Cr}$ in $\mathrm{NiO}\left(D_{\mathrm{Cr}}<D_{\mathrm{Ni}}\right)[3,4,10]$.

\section{References}

[1] WAGNER C., Corros. Sci. 9 (1969) 91.

[2] Narita T., Nishida K., Smeltzer W., J. Electrochem. Soc. 129 (1982) 209.

[3] Petot G., Armanet F., Klimczyk H., Petot-Ervas G., Solid State Ionics 50 (1992) 87.

[4] Farhi R., Petot-ERvas G., J. Phys. C 37 (1976) 438.

[5] Petot-Ervas G., Petot C., J. Phys. Chem. Solids 51 (1990) 901.

[6] Monceau D., Petot-Ervas G., Рetot C., Solid State Ionics 45 (1991) 231.

[7] Petot-Ervas G., Monceau D., Petot C., Ceram. Trans. 24 (1992) 113.

[8] SCHMALzRIED H., Reactivity Solids 1 (1981) 119.

[9] Monceau D., Petot C., Petot-Ervas G., J. Eur. Cer. Soc. 9 (1992) 193. 
[10] Petot-Ervas G., Petot C., Monceau D., Loudjani M., Solid State Ionics 53-56 (1992) 270.

[11] LeVIn R.L., WAGNer J.B., Trans. Metall. Soc. AIME 233 (1965) 159.

[12] RAPP R.A., National association of corrosion Engineers, The Ohio State University Corrosion 24 (1965) 382.

[13] STOTT F.H., WOOD G.C., WhITTLE D.P., BASTOW B.D., ShIDA Y., Solid State Ionics 12 (1984) 365.

[14] Nowotny J., Oblakowski J., Sadowski A., Bull. Acad. Sci. 33 (1985) 100. 